\title{
Brief Overview of Sweet Sorghum Irradiated by Carbon Ion Beam
}

\author{
Xicun Dong ${ }^{1}$, Wenjian $\mathrm{Li}^{1}$, Ruiyuan $\mathrm{Liu}^{1} \&$ Wenting $\mathrm{Gu}^{1}$ \\ ${ }^{1}$ Department of Radiobiology, Institute of Modern Physics, Chinese Academy of Sciences, Lanzhou, China \\ Correspondence: Xicun Dong, Radiobiology Department, Institute of Modern Physics, Chinese Academy of \\ Sciences, Lanzhou, China. Tel: 86-0931-496-9175. E-mail: dongxicun@impcas.ac.cn
}

Received: May 1, 2017

doi:10.5539/jas.v9n8p74
Accepted: May 31, $2017 \quad$ Online Published: July 15, 2017

URL: https://doi.org/10.5539/jas.v9n8p74

The research is financed by the STS project (KFJ-EW-STS-086) and Western Light Co-scholar (29Y406020) Program of the Chinese Academy of Sciences.

\begin{abstract}
Sweet sorghum [Sorghum bicolor (L.) Moench] is a $\mathrm{C}_{4}$ plant characterized by a high photosynthetic efficiency and a high biomass- and sugar- yielding crop. However, the current varieties of sweet sorghum cannot meet the rapid growth demand for bio-ethanol production because of its low sugar content in China. To breed novel varieties to provide excellent raw materials for bio-ethanol production, the dry seeds were irradiated by carbon ion beam irradiation with different doses in sweet sorghum, resulting in acquiring an early-maturity mutant at 80 Gy dose, which the growth period was stably shortened for around 20 days compared to wild-type plant. In this paper, we briefly summarized the biological effects induced by carbon ion beam, the characters of early-maturity mutant, and revealed corresponding mechanisms from the point of view of morphological, physiological and molecular levels. In conclusion, there were significant effects on sweet sorghum irradiated by carbon ion beam.
\end{abstract}

Keywords: biological effects, biological characters, carbon ion beam, sweet sorghum

\section{Introduction}

As is known to all, heavy ions irradiation is expected to increase mutation frequency and mutation spectrum, characterized by high linear energy transfer (LET) and relative biological effectiveness (RBE) (Zhou et al., 2006).Heavy ion beam has been used on many plants, such as the Artemisia annua (Inthima et al., 2014), chrysanthemum (Yamaguchi et al., 2010), wheat (Liu et al., 2013), Lotus japonicus (Luo et al., 2016), Green wandering jew (Liu et al., 2016) and Arabidopsis (Du et al., 2014; Yoshihiro et al., 2017), etc. In plants, the biological effects of heavy-ion radiation encompassed a wide range of alterations, including developmental abnormalities (Kranz, 1994), chromosomal aberrations (Ritter \& Durante, 2010; Kikuchi et al., 2009; Wei et al., 2006) and increased mutation rates (Du et al., 2014). Heavy-ion radiation-induced variations have also been found in the plant genome (Xu et al., 2006). Shikazono et al. (2005) reported that more structural alterations were induced by carbon ions in DNA than low-LET radiation. At the same time, the study also revealed that deletions were more often found in the DNA sequences of the rejoined site because of carbon ions irradiation. Sweet sorghum [Sorghum bicolor (L.) Moench] is a $\mathrm{C}_{4}$ plant characterized by a high photosynthetic efficiency and a high biomass- and sugar-yielding crop (Billa et al., 1997), a conclusion is drawn that sweet sorghum is a potential useful energy crop.The primary advantage of sweet sorghum is its high ethanol productivity, 3700 to 5600 liter/ha per year (Gibbons, 1986). However, the current varieties of sweet sorghum cannot meet the rapid growth demand in China for bio-ethanol production owing to its low sugar content. To breed novel varieties to provide excellent raw materials for bio-ethanol production from sweet sorghum, more work has been done for mutation breeding with carbon ion beam irradiation in sweet sorghum since 2006 (Dong et al., 2007; Dong et al., 2015). In this paper, we briefly summarized the biological effects induced by carbon ions, characters of early-maturity mutant, and revealed corresponding mechanism from the point of view of morphological, physiological and molecular levels.

\section{Biological Effects Induced by Carbon Ion Beam in Sweet Sorghum}

Ionizing radiation is known to have several effects on plant growth and development, ranging from stimulatory effects at low doses, harmful consequences at intermediate levels to pronounced detrimental outcomes at high doses (Cucinotta \& Durante, 2006; Durante \& Cucinotta, 2008; Veronica et al., 2001). For sweet sorghum, the 
dry seeds were firstly irradiated by carbon ion beam with different doses, including 10, 15, 20, 30, 40, 50, 80 Gy, respectively (Dong et al., 2007). The results indicated that the survival fraction of sweet sorghum presented "saddle like model" that the survival rate decreased, then increased and decreased again with irradiation doses increased. According to M1 generation effects in this irradiation experiment, the optimal mutagenic dose, 40-60 Gy, was recommended. However, the recommended dose is too low to inhibit the development of sweet sorghum. Based on above results, the dry seeds of sweet sorghum were secondly irradiated by carbon ions with doses of 120, 160, 200, and 240 Gy (Dong et al., 2008), which there was significant inhibition for germination and seedling growth after irradiation. The percentage germination and surviving fraction decreased when the dose increased, but also the seedling growth was obviously retarded at 200 and $240 \mathrm{~Gy}$. From the two experiments (Dong et al., 2007; Dong et al., 2008), the carbon ions had a marked stimulatory effect on the survival rate at low doses, with the value being $86 \%$ when the dose was at $30 \mathrm{~Gy}$, higher than that of wild-type seeds. The carbon ion irradiation led to physiological damage and the surviving fraction in the field decreased as the dose increased above 30 Gy. Especially, the physiological damage obviously increased above 200 Gy. Ultimately, the median lethal dose was estimated to be 120 Gy for sweet sorghum.

To further validated the mutagenic effects of the carbon ions, correlation analysis was carried out between the irradiation dose and the main agronomic traits according to indexes which were measured at the mature stage, including node number, plant height, stalk diameter, sugar content and single stem weight (Dong et al., 2009; Dong et al., 2015). The analysis demonstrated that the irradiation dose was negatively correlated with both the node number and the sugar content. More specifically, there was a significant negative correlation of 0.93 between irradiation dose and sugar content $(\mathrm{p}<0.01)$. However, there were positive correlations between the irradiation dose and other agronomic traits, such as plant height, stalk diameter and single plant weight (Table 1).

Table 1. The correlation coefficient between irradiation dose and the main agronomic traits of sweet sorghum

\begin{tabular}{lllllll}
\hline & $\mathrm{X} 1$ & $\mathrm{X} 2$ & $\mathrm{X} 3$ & $\mathrm{X} 4$ & $\mathrm{X} 5$ & $\mathrm{X} 6$ \\
\hline Irradiation (X1) & 1 & & & & & \\
Node number (X2) & -0.478 & 1 & & & & \\
Plant height (X3) & 0.045 & 0.569 & 1 & & & \\
Stalk diameter (X4) & 0.626 & 0.223 & 0.162 & 1 & & \\
Sugar content (X5) & $-0.930^{* *}$ & 0.564 & -0.072 & -0.490 & 1 & \\
Single stem weight (X6) & $0.868^{* *}$ & -0.158 & 0.194 & $0.805^{*}$ & $0.805^{*}$ & 1 \\
\hline
\end{tabular}

Note. ${ }^{*}$ Significant correlation at $\mathrm{p}<0.05$ level, ${ }^{* *}$ Significant correlation at $\mathrm{p}<0.01$ level.

\section{Phenotypic Characters of Early-Maturity Mutant in Sweet Sorghum}

After carbon ion irradiation, some abnormal mutants were firstly isolated at the seedling stage, such as growing point vanishing, tip curling, plant withering and etiolation (Figure 1, Dong et al., 2015). In addition, higher mutation frequencies of $9.1 \%, 8.1 \%$ and $8.5 \%$, were found for stalk thickening, sugar content and plant withering, respectively. Interestingly, an early-maturity mutant, KFJT-1, was obtained after carbon ion irradiation at $80 \mathrm{~Gy}$, which the growth period was stably shortened for around 20 days than wild-type plant, KFJT-CK (Figure 2, Dong et al., 2012). 


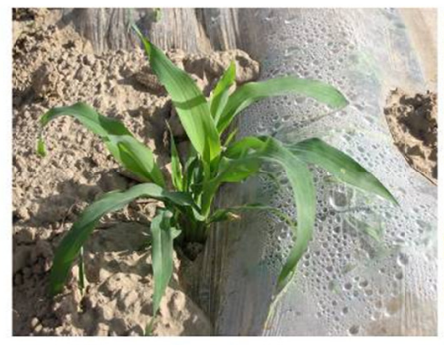

A

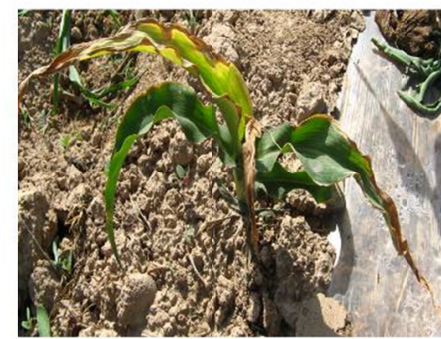

$\mathrm{D}$

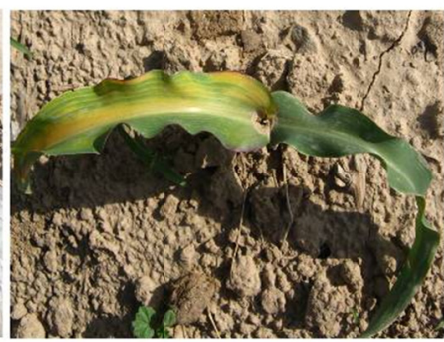

$\mathrm{B}$

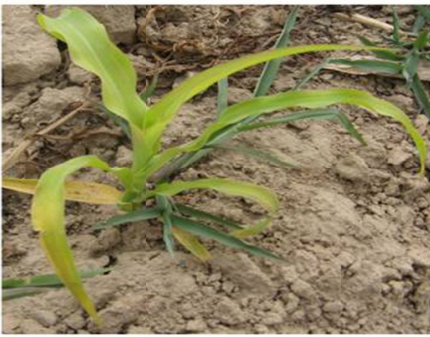

E

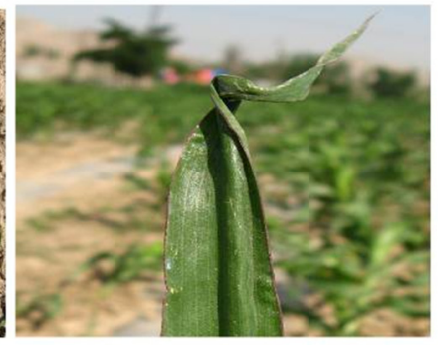

$\mathrm{C}$

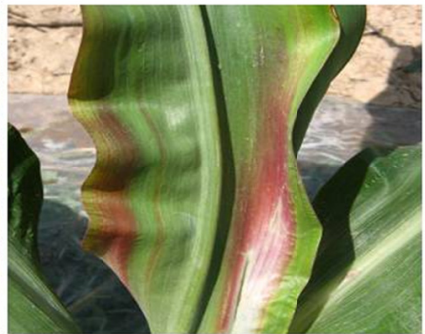

$\mathrm{F}$

Figure 1. Abnormal mutants induced by carbon ion irradiation in sweet sorghum. A is wide-type plant. B, C, D, $\mathrm{E}, \mathrm{F}$ are growing point vanishing, tip curling, plant withering, etiolation and red-brown leaf, respectively

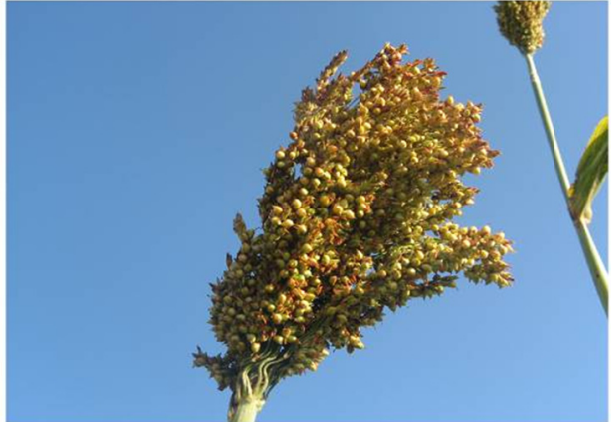

A

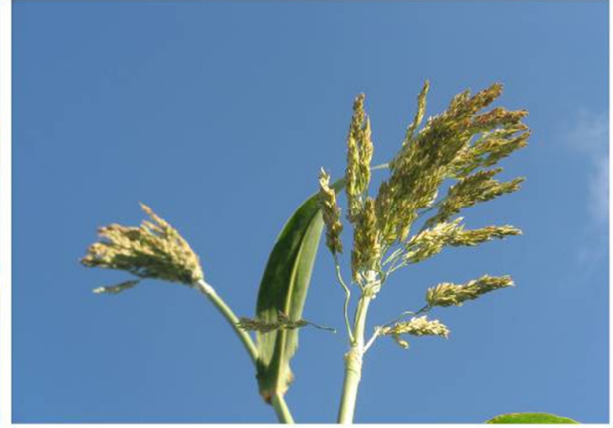

B

Figure 2. An early-maturity mutant was obtained after carbon ion irradiation in sweet sorghum. A is early-maturity mutant, B is wide-type plant

Field trials showed that the seedling growth of KFJT-1 was inhibited compared to KFJT-CK because of carbon ion beam irradiation, which similar to previous studies (Bae et al., 2004; Zhou et al., 2006). The elongation stage is key stage for sweet sorghum (Li et al., 2004), leading to obvious rise trend for the plant height of KFJT-1 and KFJT-CK during this stage. The average height of growth per day was $6.2 \mathrm{~cm}$ in KFJT-CK, faster than that of KFJT-1, the corresponding value being $5.8 \mathrm{~cm}$ (Dong \& Li, 2014), while the flowering time of KFJT-1 is earlier than that of KFJT-CK, which KFJT-1 had been at flowering stage when KFJT-CK was still at booting stage (Dong et al., 2012). In terms of pollen, the total number and viability of pollens of KFJT-1 were more than that of KFJT-CK. Further analysis showed that the meiosis of KFJT-CK was being at the stage of the first meiotic division when the meiosis of pollen mother cells was mostly turned into the second meiotic division for KFJT-1 (Liu et al., 2012).

\section{Expression Differences of Flowering Time Genes between KFJT-1 and KFJT-CK}

Plants adapt their flowering to the given environment while photoperiod is a major clue for this adaptation (Izawa, 2007). In the case of short-day plants, flowering occurs under short day condition (Takato \& Steve, 
2006). It is well known that rice is a short-day plant that induces transition from the vegetative phase to the reproductive phase when it senses a decrease in day length. Signals from light and circadian clocks are received by OsGI, the rice orthologue of Arabidopsis GIGANTEA, and it regulates expression of Heading date 1 (Hdl) (Hayama et al., 2002; Hayama et al., 2003; Song et al., 2007). Transcription of Heading date $3 a$ (Hd3a) is strongly suppressed in the $H d l$ under short day conditions, suggesting that $H d l$ can up-regulate $H d 3 a$ expression under short day conditions (Yano et al., 2001; Kojima et al., 2002). Hd3a is a rice orthologue of Arabidopsis FLOWERING LOCUS T (FT), which encode florigens that can move from the leaf to the shoot apical meristem and induce flowering in plants (Komiya et al., 2008). These genes were shown to encode a mobile flowering signal (Mathieu et al., 2007; Kobayashi, 2007). Sweet sorghum is a short-day plant and the photoperiod-sensitive sorghum variety will not flower under long days. Based on these researches, $H d 1$ and $H d 3 a$ genes were cloned from KFTJ-1 and KFJT-CK. Analysis of the PCR amplification and sequence alignment of the $H d 1$ and $H d 3 a$ genes revealed that there was no difference between KFJT-CK and KFTJ-1 in the case of $H d 1$ gene. In contrast, an insert fragment GA was found in KFTJ-1 and the corresponding fragment was not found in KFJT-CK for the Hd3a gene (Dong et al., 2015). Generally, the majority of the induced mutations were deletions in the mutants due to carbon ion irradiation (Hirano et al., 2012). A similar study (Tanaka et al., 2010) also found that 11 mutations were 1-100 bp deletions, one was a $1 \mathrm{bp}$ insertion and two had base substitutions in the 14 point-like mutations induced by carbon ions. Nonetheless, our study indicated that an early-maturity mutant, KFJT-1, not only flowered but also produced mature grain. We inferred that the photoperiod sensitivity might have been altered to photoperiod non-sensitivity by the $2 \mathrm{bp}$ insertions of $H d 3 a$ in KFTJ-1. The finding of the $H d 3 a$ gene variation provides preliminary insight into the mechanism of the photoperiodic control of flowering time in an early-maturity mutant induced by the carbon ion beam irradiation in sweet sorghum. Importantly, this speculation needs further validation in the future.

To obtain a global view of the tissue specific characteristics at the transcriptional level between KFJT-1 and KFJT-CK at seedling stage, total six DGE libraries from roots, stems and leaves were sequenced with Solexa/Illumina DGE analysis, respectively (Dong et al., 2017). In root, a total of 557 genes were up-regulated and 160 genes were down-regulated. In stem, a total of 1,232 genes were up-regulated and 928 genes were down-regulated. In leaf, total 1,577 genes were up-regulated and 754 genes were down-regulated. The total numbers of the tags-mapped genes were 717, 2160 and 2331 in root, stem and leaf, respectively. Functional analysis of gene ontology indicated that genes involved flowering time were also enriched such as "response to far red light", "pollen development" including "auxin transport", which consist with the short growth cycle of KFJT-1 compared to KFJT-CK. Specially, the metabolic pathway, "polysaccharide metabolic process", "carboxylic acid biosynthetic process" and "developmental maturation" was founded and suggested that KFJT-1 fixed higher carbon than KFJT-CK in young leaf. The enrichment analysis of biological metabolic pathways revealed that the circadian rhythm was over-represented at seedling stage. In young root, the genes involved in the circadian rhythm were mostly up-regulated including PHYA, PHYB, TOC1, APR 3, GI, LHY, CCA1 and WNK1. Whereas, in young stem, most of the genes were down-regulated including PHYA, PHYB, ARP7, CHS, TOC1 and CCA. In young leaf, six genes were involved, which three genes (PHYA, TOC1 and $A P R 3)$ were up-regulated and the other three genes (WNK1 and $C K 2 \alpha, C K 2 \beta$ ) were down-regulated. The gene $G I$ which is a typical disruption of the $P H Y B$ signal transduction pathway was also slightly up-regulated in young root.

\section{Conclusions}

The conventional breeding method takes several years to develop a new cultivar/variety from wild species. Comparatively speaking, heavy ion beam irradiation is an effective technique for mutation breeding to produce new cultivars (Cerrone et al., 2012). In this review, the optimal mutagenic dose was recommended for mutation breeding in sweet sorghum according to dose response curve. Moreover, early-maturity mutant, KFJT-1, has been identified by the Gansu Provincial Variety Approval Committee after regional trial and production test, resulting in achieving economic benefits for local governments and enterprises (Dong et al., 2016). As far as I know, this variety of sweet sorghum is firstly created using heavy ion beam mutation breeding technology in the world. Importantly, the corresponding mechanisms of biological effects, flowering time key genes and tissue-specific expression at seeding stage were systematically investigated, founding that there was a distinct biological effect on sweet sorghum irradiated by carbon ions. In brief, a marked stimulatory effect was not only discovered after carbon ion irradiation at low doses, but also significant expression differences were achieved in roots, stem, leaves for genes involved flowering time between KFTJ-1 and KFJT-CK at seeding stage.

\section{References}

Bae, C. H., Yu, J. L., Abe, T., et al. (2004). High radioactivity level of Malaysia beach sands. Proceedings of APAC, Korea (pp. 444-445). 
Billa, E., Koullas, D. P., Monties, B., \& Koukios, E. G. (1997). Structure and composition of sweet sorghum stalk components. Ind. Crops Prod., 6, 297-302. https://doi.org/10.1016/S0926-6690(97)00031-9

Cerrone, S. C., Hiroki, K., Hiroyuki, U., \& Tomoko, A. (2012). Heavy-ion beam irradiation is an effective technique for reducing major allergens in peanut seeds. Molecule Breeding, 30, 1037-1044. https://doi.org/ $10.1007 / \mathrm{s} 11032-011-9687-2$

Cucinotta, F. A., \& Durante, M. (2006). Cancer risk from exposure to galactic cosmic rays: Implications for space exploration for human beings. Lancet Oncol, 7, 431-435. https://doi.org/10.1016/S1470-2045(06) 70695-7

Dong, X. C., \& Li, W. J. (2012). Biological features of an early-maturity mutant of sweet sorghum induced by carbon ions irradiation and its genetic polymorphism. Advances in Space Research, 50, 496-501. https://doi.org/10.1016/j.asr.2012.04.028

Dong, X. C., Li, W. J., He, J. Y., \& Yu, L. X. (2007). Current effect of irradiation with $12 \mathrm{C}+6$ ions beam on mutation of sweet sorghum. J. Radiat. Res. Radiat. Process, 6, 359-362.

Dong, X. C., Li, W. J., He, J. Y., Liu, Q. F., \& Yu, L. X. (2009). Effects of main traits of sweet sorghum irradiated by carbon ions. Nuclear Techniques, 32, 146-149.

Dong, X. C., Li, W. J., He, J. Y., Yu, L. X., \& Zhou, L. B. (2008). The influence of carbon ion irradiation on sweet sorghum seeds. Nuclear Instruments and Methods in Physics Research B, 266, 123-126. https://doi.org/10.1016/j.nimb.2007.10.025

Dong, X. C., Li, W. J., Liu, R. Y., \& Gu, W. T. (2015). Phenotypic variation of sweet sorghum after carbon ion beam irradiation. Res. on Crops, 16, 162-169. https://doi.org/10.5958/2348-7542.2015.00023.6

Dong, X. C., Yan, X., \& Li, W. J. (2016). Plant mutation breeding with heavy ion irradiation at IMP. Journal of Agricultural Science, 5, 34-41. https://doi.org/10.5539/jas.v8n5p34

Dong, X. C., Yan, X., Li, W. J., Liu, R. Y., \& Gu, W. T. (2017). Tissue-specific expression profiling of seedling stage in early-maturity mutant induced by carbon ion beam in sweet sorghum. Journal of Agricultural Science, 9, 49-63. https://doi.org/10.5539/jas.v9n1p49

Du, Y., Li, W. J., Yu, L. X., Shu, Q. Y., \& Zhou, L. B. (2014). Mutagenic effects of carbon-ion irradiation on dry Arabidopsis thaliana seeds. Mutation Research/Genetic Toxicology and Environmental Mutagenesis, 759, 28-36. https://doi.org/0.1016/j.mrgentox.2013.07.018

Durante, M., \& Cucinotta, F. A. (2008). Heavy ion carcinogenesis and human space exploration. Nat. Rev. Cancer, 8, 465-472. https://doi.org/10.1038/nrc2391

Gibbons, W. R., Westby, C. A., \& Dobbs, T. L. (1986). Intermediate-scale, semicontinuous solid-phase fermentation process for production of fuel ethanol from sweet sorghum. Applied and Environmental Microbiology, 1, 115-122.

Hayama, R., Izawa, T., \& Shimamoto, K. (2002). Isolation of rice genes possibly involved in the photoperiodic control of flowering by a fluorescent differential display method. Plant Cell Physiol., 43, 494-504. https://doi.org/10.1093/pcp/pcf059

Hayama, R., Yokoi, S., Tamaki, S., Yano, M., \& Shimamoto, K. (2003). Adaptation of photoperiodic control pathways produces short-day flowering in rice. Nature, 422, 719-722. https://doi.org/10.1038/nature01549

Hirano, T., Kazama, Y., Ohbu, S., Shirakawa, Y., Liu, Y., Kambara, T., Fukunishi, N., \& Abe, T. (2012). Molecular nature of mutations induced by high-LET irradiation with argon and carbon ions in Arabidopsis thaliana. Mutation Research, 735, 19-31. https://doi.org/10.1016/j.mrfmmm.2012.04.010

Inthima, P., Otani, M., Hirano, T., Hayashi, Y., Abe, T., Nakano, M., \& Supaibulwatana, K. (2014). Mutagenic effects of heavy-ion beam irradiation on in vitro nodal segments of Artemisia annua L. Plant Cell Tiss. Organ Cult., 119, 131-139. https://doi.org/10.1007/s11240-014-0519-z

Izawa, T. (2007). Molecular diversity of photoperiodic flowering in plants. Comparative Biochemistry and Physiology A, 146, S225-S233. https://doi.org/10.1016/j.cbpa.2007.01.514

Kikuchi, S., Saito, Y., Ryuto, H., Miyatake, N., Abe, T., Tanaka, H., \& Tsujimoto, H. (2009). Effects of heavy-ion beams on chromosomes of common wheat (Triticum aestivum). Mutation Research, 669, 63-66. https://doi.org/10.1016/j.mrfmmm.2009.05.001

Kobayashi, Y., \& Weigel, D. (2007). Move on up, it is time for change-mobile signals controlling 
photoperiod-dependent flowering. Genes. Dev., 21, 2371-2384. https://doi.org/10.1101/gad.1589007

Kojima, S., Takahashi, Y., Kobayashi, Y., Mona, L., Sasaki, T., Araki, T., \& Yano, M. (2002). Hd3a, a rice ortholog of the Arabidopsis FT gene, promotes transition to flowering downstream of Hd1 under short-day conditions. Plant Cell Physiol., 43, 1096-1105. https://doi.org/10.1093/pcp/pcf156

Komiya, R., Ikegami, A., Tamaki, S., Yokoi, S., \& Shimamoto, K. (2008). Hd3a and RFT1 are essential for flowering in rice. Development, 135, 767-774. https://doi.org/10.1242/dev.008631

Kranz, A. R. (1994). Heavy ion and cosmic radiation effects in different targets of the Arabidopsis seed. Acta Astronaut., 33, 201-210. https://doi.org/10.1016/0094-5765(94)90126-0

Li, G. Y., Gu, W. B., \& Keith, C. (2004). Sweet sorghum (pp. 10-11). Agricultral Science and Technology Press, Beijing, China.

Liu, Q. F., Wang, Z. Z., Zhou, L. B., Qu, Y., Lu, D., \& Li, W. J. (2013). Relationship between plant growth and cytological effect in root apical meristem after exposure of wheat dry seeds to carbon ion beams. Nuclear Instruments and Methods in Physics Research B, 305, 9-15. https://doi.org/10.1016/j.nimb.2013.04.046

Liu, R. Y., Dong, X. C., Gu, W. T., Yu, L. X., \& Li, W. J. (2016). Variation in the phenotypic features and transcripts of thermo-sensitive leaf-color mutant induced by carbon ion beam in Green wandering jew (Tradescantia fluminensis). Scientia Horticulturae, 213, 303-313. https://doi.org/10.1016/j.scienta.2016. 11.001

Liu, R. Y., Dong, X. C., Li, W. J., He, J. Y., Qu, Y., \& Jin, W. J. (2012). Study on pollen viability and meiosis of pollen mother cells in sweet sorghum induced by carbon ion beam irradiation. J. Radiat. Res. Radiat. Process, 30, 353-358.

Luo, S. W., Zhou, L. B., Li, W. J., Du, Y., Yu, L. X., \& Feng, H. (2016). Mutagenic effects of carbon ion beam irradiations on dry Lotus japonicus seeds. Nuclear Instruments and Methods in Physics Research B, 383, 123-128. https://doi.org/10.1016/j.nimb.2016.06.021

Mathieu, J., Warthmann, N., Kuttner, F., \& Schmid, M. (2007). Export of FT protein from phloem companion cells is sufficient for floral induction in Arabidopsis. Curr. Biol., 17, 1055-1060. https://oi.org/10.1016/ j.cub.2007.05.00

Okayasu, R., Okada, M., Okabe, A., Noguchi, M., Takaura, K., \& Takahashi, S. (2006). Repair of DNA damage induced by accelerated heavy ions in mammalian cells proficient and deficient in the non-homologous end-joining pathway. Radiation Research, 165, 59-67. https://doi.org/10.1667/RR3489.1

Ritter, S., \& Durante, M. (2010). Heavy-ion induced chromosomal aberrations: A review. Mutaion Research, 701, 38-46. https://doi.org/10.1016/j.mrgentox.2010.04.007

Shikazono, N., Suzuki, C., Kitamura, S., Watanabe, H., \& Tano, S. (2005). Analysis of mutations induced by carbon ions in Arabidopsis thaliana. Journal of Experiment Botany, 56, 587-596. https://doi.org/10.1093/ jxb/eri047

Song, L. K., Lee, S., Kim, H. L., Hong, G. N., \& An, G. (2007). OsMADS51 is a short-day flowering promoter that functions upstream of Ehd1, OsMADS14, and Hd3a. Plant Physiol., 145, 1484-1494. https://doi.org/ 10.1104/pp.107.103291

Takato, I., \& Steve, A. K. (2006). Photoperiodic control of flowering: Not only by coincidence. Trends in Plant Science, 11, 550-558. https://doi.org/10.1016/j.tplants.2006.09.004

Tanaka, A., Shikazono, N., \& Hase, Y. (2010). Studies on biological effects of ion beams on lethality, molecular nature of mutation, mutation rate, and spectrum of mutation phenotype for mutation breeding in higher plants. Journal of Radiation Research, 51, 223-233. https://doi.org/10.1269/jrr.09143

Veronica, D. M., Carmen, A., Diana, P., \& Marco, D. (2011). Effects of sparsely and densely ionizing radiation on plants. Radiat. Environ. Biophys., 50, 1-19. https://doi.org/10.1007/s00411-010-0343-8

Wei, L. J., Yang, Q., Xia, H. M., Furusawa, Y., Guan, S. H., Xin, P., \& Sun, Y. Q. (2006). Analysis of cytogenetic damage in rice seeds induced by energetic heavy ions on-ground and after spaceflight. Journal of Radiation Research, 47, 273-278. https://doi.org/10.1269/jrr.0613

Xu, J. L., Wang, J. M., Sun, Y. Q., Wei, L. J., Luo, R. T., Zhang, M. X., \& Li, Z. K. (2006). Heavy genetic load associated with the subspecific differentiation of japonica rice (Oryza sativa ssp. Japonica L.). Journal of Experiment Botany, 57, 2815-2824. https://doi.org/10.1093/jxb/er1046 
Yamaguchi, H., Shimizu, A., Hase, Y., Tanaka, A., Shikazono, N., Degi, K., \& Morishita, T. (2010). Effects of ion beam irradiation on mutation and nuclear DNA content in chrysanthemum. Breeding Science, 60, 398-404. https://doi.org/10.1270/jsbbs.60.398

Yano, M., Katayose, Y. C., Ashikari, M., Yamanouchi, U., \& Sasaki, T. (2001). Hd1, a major photoperiod sensitivity quantitative trait locus in rice, is closely related to the Arabidopsis flowering time gene CONSTANS. Plant Cell, 12, 2473-2484. https://doi.org/10.1105/tpc.12.12.2473

Yoshihiro, H., Shigeki, N., Issay, N., \& Yutaka, O. (2017). Effects of ion beam irradiation on size of mutant sector and genetic damage in Arabidopsis. Nuclear Instruments and Methods in Physics Research B, 391, 14-19. https://doi.org/10.1016/j.nimb.2016.11.023

Zhou, L. B., Li, W. J., Ma, S., Dong, X. C., \& Yu, L. X. (2006). Effects of ion beam irradiation on adventitious shoot regeneration from in vitro leaf explants of Saintpaulia ionahta. Nuclear Instruments and Methods in Physics Research B, 244, 349-353. http://dx.doi. 10.1016/j.nimb.2005.10.034

\section{Copyrights}

Copyright for this article is retained by the author(s), with first publication rights granted to the journal.

This is an open-access article distributed under the terms and conditions of the Creative Commons Attribution license (http://creativecommons.org/licenses/by/4.0/). 